\title{
Information for Action: The Power of Surveillance
}

\author{
Gagandeep Kang ${ }^{1} \cdot$ Amrita Sekhar $^{2}$
}

Received: 18 December 2020 / Accepted: 18 December 2020 / Published online: 4 February 2021

(C) Dr. K C Chaudhuri Foundation 2021

That rotavirus vaccines are made in India, by India, and for India, and now for the world, is one of the most incredible success stories of public health in our country, and one of which we should all be justifiably proud. We, perhaps, might not have had the indigenous rotavirus vaccines so fast after the rest of the world, if it had not been for one of the giants in pediatric research in India, Dr M. K. Bhan, who, as a young paediatrician at the All India Institute of Medical Sciences in Delhi, identified that a strain of rotavirus that exclusively infected neonates also protected the infected neonates from severe rotavirus gastroenteritis during infancy [1].

In Vellore, rotaviruses had already been identified as the cause of gastroenteritis using electron microscopy in the 1970s [2]. In the 1980s, enzyme immunoassays greatly simplified identification of rotaviruses and began to be used for research studies, but two problems persisted. The first was that since treatment of diarrhea was easier and cheaper than ordering a diagnostic tests, testing for diarrheal etiology was limited to cases in medical college hospitals or for research projects, and even there, tended to be limited to bacterial pathogens. The second was that in institutions that did test for rotavirus as part of research projects, the relatedness of strains could only be studied using two very cumbersome approaches. The first was of breaking open the virus, running the RNA on a gel, and staining the RNA with silver. The other approach was to study the viruses, using monoclonal antibodies directed against surface viral epitopes, but these monoclonal antibodies were a research tool, in limited supply and precious. When rotavirus PCRs became possible in the 1990s, this was a game changer

Amrita Sekhar

amrita.sekhar@gmail.com

1 The Wellcome Trust Research Laboratory, Division of Gastrointestinal Sciences, Christian Medical College, Vellore, Tamil Nadu, India

2 Translational Health Science and Technology Institute, NCR Biotech Science Cluster, 3rd Milestone, Faridabad-Gurugram Expressway, PO box \#04, Faridabad, Haryana 121001, India for the study of human and animal rotaviruses, defining their diversity, patterns of circulation, and their zoonotic potential [2].

Although rotavirus vaccine research started in the 1980 s, it became evident in the 1990s, that rotavirus surveillance was going to be essential to define the burden of disease, and thus inform decision-making about vaccines when they became available. Led by Dr Bhan's collaborator, Dr R. I. Glass of the Centers for Disease Control and Prevention (CDC), surveillance was established first in the US, and then increasing through a series of young scientists who trained at the CDC, in different parts of the world. Dr Bhan built a small network of laboratories in India for rotavirus surveillance in the 1990s as the first vaccine was licensed. When the vaccine was withdrawn because of an association with intussusception, India amplified its own work on the vaccine candidate first identified by Dr Bhan and taken forward under the Indo-US Vaccine Action Plan [3]. In parallel with the development of the vaccine in India, rotavirus surveillance now attempting to use standardized approaches to recruitment, data collection and testing was established with support from the Indian Council for Medical Research. The network went from 7 locations to 11 locations and generated very important data that showed that if standardized methods were used, the rotavirus prevalence in hospitalized diarrhea was almost double what had been reported in small individual studies until that time [4]. Not only that, the data were consistent with more than one-third of all hospitalized acute gastroenteritis being associated with rotavirus, whether in the north, south, east, or west.

These studies were critical, because they demonstrated that the problem of rotavirus gastroenteritis was larger than had been recognized earlier and that every part of the country was affected, showing the clear need for a vaccine. As this data were being generated, the vaccines were moving forward in their development cycle. By 2011-12, the Indian Council for Medical Research had expanded its surveillance to include 28 hospitals and 11 laboratories, which expanded earlier data collection to over 20,000 children over a four year period, and showed that the patterns of disease persisted even if the 
infecting genotypes of the virus changed with time and in different locations [5]. The National Technical Advisory Group on Immunization used these data to make the decision to recommend to the Ministry of Health and Family Welfare to introduce rotavirus vaccines into the national immunization programme.

It was only because an increasingly ambitious surveillance system had delivered increasingly higher quality data over a period of decades demonstrating the size and scale of the problem that a vaccine for diarrhea, a neglected disease entity, could be considered as an unambiguous case for investment. The rotavirus-vaccine introduction began in 2016 with a phased approach, adding states every year as vaccine availability increased, such that by 2019 , the entire country was covered by the national immunization programme using two indigenous vaccines. Having grown in ambition through participation in multiple iterations of the rotavirus surveillance network, the group became even stronger, and established for the first time in India, a surveillance programme to measure the safety and effectiveness of a newly introduced vaccine. This was not simple, because new sites in the states that were introducing vaccines had to be included, trained, and monitored. The papers in this issue are a result of that ambitious approach to post-introduction surveillance, generating data that will contribute to a separate overarching analysis of safety and effectiveness. But in addition to the data combined for robustness of analysis, there are many descriptions of findings and analysis that are important at the local and national level, on disease burden, patterns, and safety issues. The reports by location, including papers from Tirupati, Rohtak, Mewat, Chandigarh, Tanda, Bhubaneswar, Sonepat, Indore, Bijnor, Kakinada, and Varanasi [6-19], by clinical features from Mewat in Haryana and Cuttack in Odisha, the molecular characterization from sites in Odisha, Haryana and Rajasthan [11-13, 20-22], the safety data from the sites in Odisha, Haryana, Tamil Nadu, and Rajasthan [23-26] and the nutritional status and its association with diarrheal illness from Mewat [27] round out the data to present a comprehensive picture of rotavirus disease and burden in India.

Building a community of practice enhances the ability to learn from each other, and this has certainly been the case of rotavirus surveillance. However, when thinking about the sustainability of such networks, it is hard to imagine an increasing number of vertical programmes that run forever. It is important to have a holistic view so that the next generation of surveillance focuses on the future, putting the child and her/his illnesses and the community at the center and not the pathogen. A network can only deliver when all its components function well together, and in this case, the many rotavirus networks have shown that it is possible to initiate and conduct clinical and laboratory surveillance at a high level. Rotavirus surveillance has consistently provided information for action. We must now go beyond to integrated surveillance that continues to support public health preparedness and action.

\section{Compliance with Ethical Standards}

Conflict of Interest None.

\section{References}

1. Bhan MK, Lew JF, Sazawal S, Das BK, Gentsch JR, Glass RI. Protection conferred by neonatal rotavirus infection against subsequent rotavirus diarrhea. J Infect Dis. 1993;168:282-7.

2. Kang G. Rotavirus in India: forty years of research. Indian Pediatr. 2016;53:569-73.

3. Bhandari N, Rongsen-Chandola T, Bavdekar A, et al. Efficacy of a monovalent human-bovine (116E) rotavirus vaccine in Indian infants: a randomised, double-blind, placebo-controlled trial. Lancet. 2014;383:2136-43.

4. Kang G, Desai R, Arora R, et al. Diversity of circulating rotavirus strains in children hospitalized with diarrhea in India, 2005-2009. Vaccine. 2013;31:2879-83.

5. Girish Kumar CP, Giri S, Chawla-Sarkar M, et al. Epidemiology of rotavirus diarrhea among children less than 5 years hospitalized with acute gastroenteritis prior to rotavirus vaccine introduction in India. Vaccine. 2020;38(51):8154-60.

6. Badur M, Reddy Pidugu VK, Kasala L, Reddy NS, Thiyagarajan V. Acute gastroenteritis in children below 5 years of age at Tirupati, Andhra Pradesh, India post introduction of rotavirus vaccine into national immunization programme. Indian J Pediatr. 2020. https:// doi.org/10.1007/s12098-020-03606-3.

7. Dalal P, Gathwala G, Singh J, Nair NP, Thiyagarajan V. Gastroenteritis in Haryana, India post introduction of rotavirus vaccine. Indian J Pediatr. 2020. https://doi.org/10.1007/s12098-02003614-3.

8. Goel AK, Chawla S, Dhingra A, Thiyagarajan V, Nair NP. Rotavirus diarrhea and its determinants among under five children admitted in a tertiary care hospital of southern Haryana, India. Indian J Pediatr. 2020. https://doi.org/10.1007/s12098-02003616-1.

9. Gupta M, Bansal A, Bansal A, et al. Epidemiology of acute gastroenteritis caused by rotavirus among children less than five years old admitted in hospital, in north India. Indian J Pediatr. 2020. https:// doi.org/10.1007/s12098-020-03619-y.

10. Sharma J, Chaudhary S, Bajaj M, Nair NP, Thiyagarajan V. Rotavirus gastroenteritis hospitalizations among under-5 children in northern India. Indian J Pediatr. 2020. https://doi.org/10.1007/ s12098-020-03621-4.

11. Pradhan SK, Panigrahi S, Padhi PS, Thiyagarajan V, Satpathy SK. Genetic characteristics of rotavirus acute gastroenteritis among hospitalized children of Odisha in eastern India. Indian J Pediatr. 2020. https://doi.org/10.1007/s12098-020-03610-7.

12. Ghoshal V, Nayak MK, Misra N, Kumar R, Reddy NS, Mohakud NK. Surveillance and molecular characterization of rotavirus strains circulating in Odisha, India after introduction of rotavac. Indian J Pediatr. 2020. https://doi.org/10.1007/s12098-020-03622-3.

13. Rawal M, Raikwar P, Nair NP, Thiyagarajan V, Lingam R. Demographic profile and genotypic distribution of rotavirus gastroenteritis from rural Haryana, India. Indian J Pediatr. 2020. https:// doi.org/10.1007/s12098-020-03612-5.

14. Mohanty P, Kumar D, Mansingh A, Thiyagarajan V, Reddy NS, Ray RK. Rotavirus gastroenteritis hospitalizations among under- 
five children in Bhubaneswar, Odisha, India. Indian J Pediatr. 2020. https://doi.org/10.1007/s12098-020-03607-2.

15. Vashishtha VM, Nair NP, Ahmad M, Vashishtha I, Thiyagarajan V. Rotavirus gastroenteritis in western Uttar Pradesh, India. Indian J Pediatr. 2020. https://doi.org/10.1007/s12098-020-03623-2.

16. Gupta V, Aggarwal P, Kumar B, Nair NP, Thiyagarajan V, Lingam R. Rotavirus gastroenteritis in eastern Uttar Pradesh, India. Indian J Pediatr. 2020. https://doi.org/10.1007/s12098-020-03625-0.

17. Goru KB, Manikyamba D, Muppidi VP, et al. Two-year prevalence of rotavirus among under-five children admitted with acute gastroenteritis in Andhra Pradesh, India. Indian J Pediatr. 2020. https:// doi.org/10.1007/s12098-020-03608-1.

18. Chaudhary P, Jain H, Nair NP, Thiyagarajan V. Rotavirus diarrhea in hospitalized under-5 children in Madhya Pradesh, India and the prevalent serotypes after vaccine introduction. Indian J Pediatr. 2020. https://doi.org/10.1007/s12098-020-03638-9.

19. Pradhan SK, Panigrahi S, Padhi PS, et al. Clinical profile, riskfactors and outcome of rotaviral diarrhea and non-rotaviral diarrhea among under-five children at Cuttack, Odisha, India. Indian J Pediatr. 2020. https://doi.org/10.1007/s12098-020-03598-0.

20. Gupta RK, Vajpayee S, Agrawal R, Goyal AK, Nair NP, Thiyagarajan V. Post vaccination epidemiology and genotyping of rotavirus gastroenteritis at a tertiary care centre of north-east Rajasthan. Indian J Pediatr. 2020. https://doi.org/10.1007/s12098020-03569-5.

21. Sharma P, Katewa S, Meel SK, et al. Clinicoepidemiological profile and genetic characterization of circulating rotavirus strain among children $<5$ years hospitalized for acute gastroenteritis in western Rajasthan, India. Indian J Pediatr. 2020. https://doi.org/10.1007/ s12098-020-03628-x.
22. Jain B, Goyal S, Poswal L, Dangi R, Nair NP, Thiyagarajan V. Epidemiology and genotype distribution of rotavirus gastroenteritis in under-five children of south Rajasthan, India. Indian J Pediatr. 2020. https://doi.org/10.1007/s12098-020-03626-z.

23. Pradhan SK, Dash M, Ray RK, et al. Childhood intussusception after introduction of indigenous rotavirus vaccine: hospital-based surveillance study from Odisha, India. Indian J Pediatr. 2020. https://doi.org/10.1007/s12098-020-03627-y.

24. Gupta M, Kanojia R, Bansal A, et al. Epidemiology of hospitalized intussusception cases from northern states in India. Indian J Pediatr. 2020. https://doi.org/10.1007/s12098-020-03609-0.

25. Girish Kumar CP, Reddy NS, Subramanian S, et al. Epidemiology of intussusception hospitalizations in children under 2 years of age post rotavirus vaccine introduction in Tamil Nadu and Puducherry, India. Indian J Pediatr. 2020. https://doi.org/10.1007/s12098-02003597-1.

26. Goyal AK, Gupta RK, Jain B, et al. A hospital-based multi-centric study to determine the clinico-epidemiological profile of intussusception in children $<2$ years in Rajasthan, India. Indian J Pediatr. 2020. https://doi.org/10.1007/s12098-020-03601-8.

27. Chawla S, Goel AK, Thiyagarajan V, Nair NP. Nutritional assessment and its association with rotavirus positivity among under five children admitted with diarrhea in a tertiary care hospital of southern Haryana, India. Indian J Pediatr. 2020. https://doi.org/10.1007/ s12098-020-03611-6.

Publisher's Note Springer Nature remains neutral with regard to jurisdictional claims in published maps and institutional affiliations. 